\title{
Eruptive Keratoacanthomas in a Red Tattoo
}

Laura Linares-Gonzalez, Teresa Ródenas-Herranz, Marina Galvez-Moreno, *Ricardo Ruiz-Villaverde

$$
\text { أورام قرنية شوكية طفحية في وشم أحمر }
$$

لورا ليناريس غونزاليس، تيريزا روديناس-هيرانز، مارينا جالفيز-مورينو، ريكاردو رويز فيلافيردي

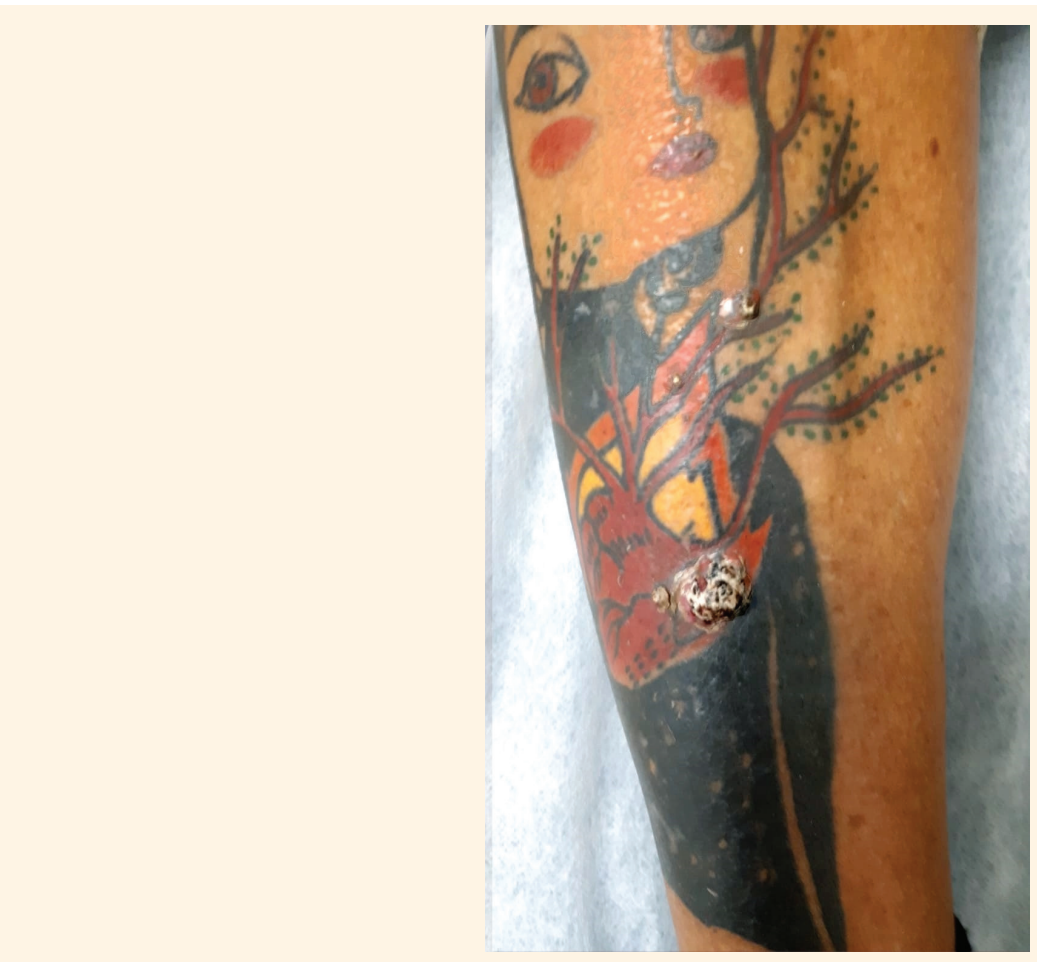

Figure 1: Hyperkeratotic nodules appearing on the red ink of a tattoo on the leg of a 65-year-old female patient.

A 65-YEAR-OLD FEMALE PATIENT WITH extensive body tattoos and no medical history of interest, presented at the outpatient dermatological clinic, University Hospital San Cecilio, Granada, Spain, with a two-week history of several rapidly growing crusted nodules on the red tattoo ink that had been done one month prior [Figure 1]. On clinical examination, several well-demarcated, skin-coloured hyperkeratotic nodules with central ulcerations and crateriform surfaces, ranging in size between $0.4-2 \mathrm{~cm}$ on the right leg were discovered. No other lesions could be observed. Haematoxylin and eosin examination and cultures for bacteria, fungi and atypical mycobacteria were made from samples taken by cutaneous biopsy. Histological examination showed findings compatible with eruptive keratoacanthomas (KA) and an intense chronic histiocytic dermatitis in response to the exogenous pigments in the underlying dermis [Figure 2]. After one week, some of the lesions had resolved spontaneously and the largest lesion was treated with intralesional methotrexate $15 \mathrm{mg} / \mathrm{dL}$ every other week, which resulted in a mild decrease in size. A complete removal of the lesion was performed, with no recurrence after 12-months of follow-up.

\section{Comment}

$\mathrm{KA}$ is a relatively common keratinising squamous neoplasm that only rarely progresses to metastatic carcinoma, in spite of its initial rapid growth. This 


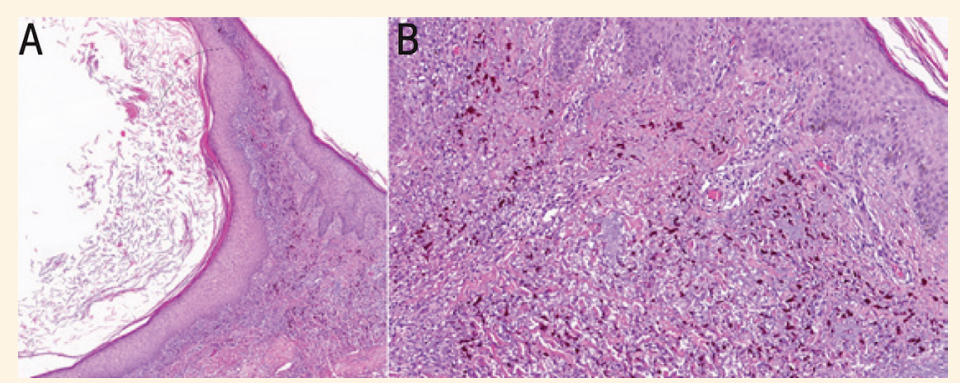

Figure 2: A: Haematosilin and eosin stain at x10 maginification showing proliferation of atypical keratinocytes with crateriform appearance and central corneal material. B: Haematosilin and eosin stained dermis at x20 maginification showing intense mixed inflammatory infiltrate predominantly histiocytic and subcutaneous cellular tissue with abundant exogenous pigment.

lesion usually presents as a solitary dome-shaped, skincoloured nodule with a central keratinous core, most commonly on sun-exposed skin areas of middle-aged or elderly people. Involution may occur spontaneously after a few months. ${ }^{1}$

Eruptive KA has been rarely described in the literature. Although its origin remains uncertain, several factors have been associated with the development of these lesions, including ultraviolet light exposure, genetic background, carcinogens, immunosuppression, viruses and various types of skin trauma. ${ }^{2}$

Kluger and Koljonen reported 50 cases of skin cancers on tattoos, 23 of which were squamous carcinoma or $\mathrm{KA}$; in a case-series of 8 patients with 11 tattoo associated KA, $82 \%$ of the cases occurred in red tattoo ink, which is well known to be the most reactive of ink colours. ${ }^{2}$ This is possibly related to the inflammatory nature of its specific components. The physiopathology of KA formation remains unclear. It has been postulated that KA develops as a result of hypersensitivity to the ink or due to trauma or viral infection from the tattooing process. Another theory postulates that the ink itself may possess carcinogenic properties. $^{3}$ The composition of tattoo inks has not been properly regulated and some components have been classified by the International Agency for Research on Cancer as possibly carcinogenic to humans (e.g. mercury, cobalt salts and carbon black) or carcinogenic to humans (e.g. cadmium). ${ }^{2}$ On the other hand, some authors consider KA formation to be a reactive response rather than a neoplastic condition. Junqueira et al. hypothesised that the skin tries to eliminate the ink like a foreign body by the development of granulomas. ${ }^{4}$

Differential diagnosis of KA arising within tattoos may include mycobacterial or fungal infections, foreign body reactions, pseudolymphomatous reactions or sarcoidosis. Histological examination should always be performed, which is considered the gold standard to confirm the diagnosis and rule out squamous cell carcinoma.

Multiple treatment modalities have been suggested for KA. While spontaneous regression has been described; in fact, several small nodules resolved spontaneously in our case. For lesions not resolving on their own, surgical modalities may be considered as the first-line treatments. This includes shave excision, curettage, cautery and surgical excision; other options include intralesional therapy with steroids, methotrexate, 5-fluorouracil (5-FU) or bleomycin and topical agents, such as imiquimod or 5-FU. Systemic modalities include steroids, methotrexate or retinoids. Acitretin, a metabolite of etretinate that inhibits the growth of keratinocytes, used in a dose of $25 \mathrm{mg}$ daily is the preferred treatment for recalcitrant lesions and for patients in whom surgery or radiation therapy can cause aesthetic defects. ${ }^{5}$ Finally, ablative therapies such as radiation therapy, laser therapy, cryotherapy or photodynamic therapy may be useful, especially for small lesions. ${ }^{6}$

\section{References}

1. Rinker MH, Fenske NA, Scalf LA, Glass LF. Histologic variants of squamous cell carcinoma of the skin. Cancer Control 2001; 8:354-63. https://doi.org/10.1177/107327480100800409.

2. Kluger N, Koljonen V. Tattoos, inks, and cancer. Lancet Oncol 2012; 13:e161-8. https://doi.org/10.1016/S1470-2045 (11)70340-0

3. Muñoz Borrás D. Allergic Reactions to Tattoo Inks: A New Diagnostic Challenge. Las reacciones alérgicas frente a las tintas de los tatuajes, un nuevo reto diagnóstico. Actas Dermosifiliogr 2018; 109:100. https://doi.org/10.1016/j.ad.2017.10.010.

4. Junqueira AL, Wanat KA, Farah RS. Squamous neoplasms arising within tattoos: Clinical presentation, histopathology and management. Clin Exp Dermatol 2017; 42:601-6. https:// doi.org/10.1111/ced.13183.

5. Gon A dos S, Minelli L, Meissner MCG. Keratoacanthoma in a tattoo. Dermatol Online J 2009; 15:9.

6. Alloo A, Garibyan L, LeBoeuf N, Lin G, Werchniak A, Hodi FS Jr, et al. Photodynamic therapy for multiple eruptive keratoacanthomas associated with vemurafenib treatment for metastatic melanoma. Arch Dermatol 2012; 148:363-6. https:// doi.org/10.1001/archdermatol.2011.3080. 